University of Nebraska - Lincoln

DigitalCommons@University of Nebraska - Lincoln

Papers in Plant Pathology

Plant Pathology Department

2013

Isolation and characterization of the grain mold fungi Cochliobolus and Alternaria spp. from sorghum using semiselective media and DNA sequence analyses

Deanna L. Funnell-Harris

USDA-ARS, Deanna.Funnell-Harris@ars.usda.gov

Louis K. Prom

USDA-ARS, louis.prom@ars.usda.gov

Jeffrey F. Pedersen

USDA-ARS, jpedersen1@unl.edu

Follow this and additional works at: http://digitalcommons.unl.edu/plantpathpapers

Part of the Other Plant Sciences Commons, Plant Biology Commons, and the Plant Pathology Commons

Funnell-Harris, Deanna L.; Prom, Louis K.; and Pedersen, Jeffrey F., "Isolation and characterization of the grain mold fungi Cochliobolus and Alternaria spp. from sorghum using semiselective media and DNA sequence analyses" (2013). Papers in Plant Pathology. 458.

http://digitalcommons.unl.edu/plantpathpapers/458

This Article is brought to you for free and open access by the Plant Pathology Department at DigitalCommons@University of Nebraska - Lincoln. It has been accepted for inclusion in Papers in Plant Pathology by an authorized administrator of DigitalCommons@University of Nebraska - Lincoln. 


\title{
Isolation and characterization of the grain mold fungi Cochliobolus and Alternaria spp. from sorghum using semiselective media and DNA sequence analyses
}

Deanna L. Funnell-Harris, Louis K. Prom, and Jeffrey F. Pedersen

\begin{abstract}
Mold diseases, caused by fungal complexes including Alternaria, Cochliobolus, and Fusarium species, limit sorghum grain production. Media were tested by plating Fusarium thapsinum, Alternaria sp., and Curvularia lunata, individually and competitively. Dichloran chloramphenicol rose bengal (DRBC) and modified V8 juice (ModV8) agars, found to be useful, were compared with commonly used agar media, dichloran chloramphenicol peptone (DCPA) and pentachloronitrobenzene (PCNB). Radial growth, starting with mycelia or single-conidia and hyphal tips, demonstrated an effect of media. For isolation of grain fungi, DRBC and ModV8 were similar or superior to DCPA and PCNB. When seedlings were inoculated with conidia of C. lunata, Alternaria sp., F. thapsinum, or mixtures, the percentage of root infection ranged from $28 \%$ to $77 \%$. For mixed inoculations, shoot weights, lesion lengths, and percentage of root infections were similar to F. thapsinum inoculations; most colonies recovered from roots were F. thapsinum. For Alternaria grain isolates, 5 morphological types, including Alternaria alternata, were distinguished by colony morphologies and conidial dimensions. Sequence analysis using a portion of the endo-polygalacturonase gene was able to further distinguish isolates. Cochliobolus isolates were identified morphologically as C. lunata, Curvularia sorghina, and Bipolaris sorghicola. Multiple molecular genotypes were apparent from rRNA internal transcribed spacer region sequences from Cochliobolus grain isolates.
\end{abstract}

Key words: Alternaria, Cochliobolus, Fusarium, semiselective media, Sorghum bicolor.

Résumé : La moisissure produite par des complexes de champignons formés des espèces Alternaria, Cochliobolus et Fusarium limite la production de sorgho. Des milieux de culture ont été étudiés en ensemençant Fusarium thapsinum, Alternaria sp. et Curvularia lunata de manière individuelle et compétitive. La gélose Dichloran Rose-bengale Chloramphénicol (DRBC) et la gélose au jus V8 modifiée (ModV8), qui s'étaient avérées utiles, ont été comparées à d'autres géloses couramment utilisées, la gélose Dichloran Chloramphénicol Peptone (DCPA) et la gélose pentachloronitrobenzène (PCNB). L'examen de la croissance radiale, commençant par les mycéliums ou les conidies uniques et les têtes des hyphes, a démontré que les milieux exerçaient un effet. Les milieux DRBC et ModV8 étaient similaires ou supérieurs au DCPA et au PCNB quant à l'isolement des champignons des céréales. Lorsque les semis étaient inoculés avec les conidies de C. lunata, Alternaria sp., F. thapsinum ou des mélanges de celles-ci, le pourcentage d'infection des racines allait de $28 \%$ à $77 \%$. La taille des pousses, la longueur des lésions et le pourcentage d'infection obtenus après une inoculation mixte ou une inoculation avec $F$. thapsinum étaient similaires ; la plupart des colonies récupérées des racines appartenaient à $F$. thapsinum. En ce qui concerne les isolats de Alternaria présents sur les céréales, cinq types morphologiques dont Alternaria alternata se distinguaient par la morphologie des colonies et les dimensions des conidies. L'analyse de séquence d'une portion du gène codant l'endo-polygalacturonase a permis de distinguer davantage les isolats. Les isolats de Cochliobolus ont été identifiés morphologiquement comme étant $C$. lunata, Curvularia sorghina et Bipolaris sorghicola. De multiples génotypes moléculaires étaient mis en évidence par les séquences de la région transcrite de l'espaceur interne de l'ARNr des isolats de Cochliobolus provenant des céréales. [Traduit par la Rédaction]

Mots-clés : Alternaria, Cochliobolus, Fusarium, milieu semi-sélectif, Sorghum bicolor.

\section{Introduction}

Sorghum has been developed for use in food products and for bioenergy (Carpita and McCann 2008; Sarath et al. 2008; Taylor et al. 2006). The responses of some newly developed lines to fungal pathogens have been unexpected. For example, grain of lowlignin lines was less susceptible to Fusarium spp. infecting nearisogenic wild-type grain (Funnell-Harris et al. 2010), and sorghum with reduced production of antimicrobial plant pigments was less susceptible to head smut, caused by Sporisorium reilianum (Kühn) Langdon \& Fullerton, than near-isogenic pigmented lines (D.L. Funnell-Harris, L.K. Prom, S.E. Sattler, and J.F. Pedersen, unpub- lished). Thus, further research of fungal pathogens in newly developed sorghum lines is warranted.

A major limitation to sorghum production is grain mold disease (Sharma et al. 2010), caused by a fungal complex (Tarekegn et al. 2006) that includes Fusarium, Alternaria, and Cochliobolus species. Infection can significantly reduce grain yield and quality or contribute to deterioration during storage (Castor and Frederiksen 1982; Stack and Pedersen 2003). Several Fusarium species infect sorghum grain (Funnell-Harris et al. 2010; Lincy et al. 2011; Sharma et al. 2011), while relatively few species of Alternaria and Cochliobolus have been reported (Navi et al. 2005; Tarekegn et al. 2006). Commonly isolated species are Fusarium thapsinum Klittich, Leslie,

Received 24 October 2012. Revision received 28 November 2012. Accepted 30 November 2012.

D.L. Funnell-Harris and J.F. Pedersen. USDA-ARS, Grain, Forage and Bioenergy Research Unit, University of Nebraska, Department of Plant Pathology, 137 Keim Hall, UNL-East Campus, Lincoln, NE 68583-0937, USA.

L.K. Prom. USDA-ARS, Southern Plains Agricultural Research Center, Crop Germplasm Research Unit, 2881 F \& B Road, College Station, TX 77845, USA.

Corresponding author: Deanna L. Funnell-Harris (e-mail: Deanna.Funnell-Harris@ars.usda.gov). 
Nelson \& Marasas 1997 (teleomorph Gibberella thapsina); Alternaria alternata (Fr.) Keissl. 1912; and Curvularia lunata (Wakker) Boedijn 1933 (teleomorph Cochliobolus lunatus Nelson \& Haasis 1964) (Funnell-Harris and Pedersen 2008; Funnell-Harris et al. 2010; Lincy et al. 2011; Navi et al. 2005; Sharma et al. 2011; Tarekegn et al. 2006).

The major routes of grain infection by these fungi are likely to be via the floret and developing grain (Menkir et al. 1996; Navi et al. 2005). It is also possible that grain can be infected systemically from plants grown from infected grain or infected through roots or crowns, as has been observed in other grains (Al-Sadi and Deadman 2010; Murillo-Williams and Munkvold 2008). Thus, the goal of the present study was to identify media that would allow for isolation of Alternaria, Cochliobolus, and Fusarium spp. from sorghum grain as well as more fragile tissues such as roots.

Previously, peptone-based media containing the fungicide pentachloronitrobenzene (PCNB) (Nash and Snyder 1962) or the fungicide dichloran with the antibiotic chloramphenicol (dichloran chloramphenicol peptone agar or DCPA) (Andrews and Pitt 1986) were commonly used for screening for Fusarium and Alternaria spp. in grain (Andrews and Pitt 1986; Rabie et al. 1997). The focus of the current study was (i) to establish semiselective media that would allow isolation of Cochliobolus as well as Alternaria and Fusarium spp. from sorghum and (ii) to morphologically, using culture media, and molecularly, using sequences from DNA regions, characterize species of Cochliobolus and Alternaria found in sorghum grain. Besides PCNB and DCPA, 2 other media, dichloran rose bengal chloramphenicol (DRBC) agar and a modification of V8 juice agar (ModV8) were compared. Field-grown grains were plated onto the 4 media to determine isolation frequency of Cochliobolus, Alternaria, and Fusarium spp. on each medium. The media DRBC and ModV8 also were tested for recovery of sorghum pathogens C. lunata, Alternaria sp., and F. thapsinum from infected seedling roots. Cochliobolus and Alternaria isolates from sorghum grain were characterized using colony morphologies on media, conidial dimensions, and by comparing sequences from 3 (Cochliobolus) or 4 (Alternaria) DNA regions with those in GenBank.

\section{Materials and methods}

\section{Maintenance of cultures, production of conidia, and storage of fungi}

Medium for maintenance of working stocks of fungi was onehalf strength potato dextrose agar (PDA), prepared using potato dextrose broth (Becton, Dickinson and Co. (BD), Sparks, Maryland) and amended with $100 \mu \mathrm{mol} / \mathrm{L}$ ampicillin (Sigma-Aldrich (SA), St. Louis, Missouri). The following techniques have proven to work well in this laboratory for production of conidia for use in assays and for storage of most Fusarium, Alternaria, and Cochliobolus grain sorghum isolates. For production of Fusarium conidia, an agar block was aseptically cut from a 5-day-old PDA culture and transferred to $1.5 \%$ agar containing $80 \mathrm{mmol} / \mathrm{L}$ potassium chloride $(\mathrm{KCl})$, then incubated 5-7 days at room temperature. For production of Alternaria conidia, mycelia were transferred from a 5-dayold PDA culture by point inoculation at the center of $2 \%$ water agar prepared with purified water (Labconco, Kansas City, Missouri), and sterile $1 \mathrm{~cm}^{2}$ filter paper (Whatman No. 1; Whatman International, Ltd., Maidstone, Great Britain) was placed over the inoculation site; cultures were incubated at least 2 weeks at room temperature. Production of Cochliobolus conidia was conducted by point inoculation onto corn meal agar (CMA) (BD); the colony was allowed to grow at room temperature for 7-10 days, after which sterilized $1 \mathrm{~cm}^{2}$ filter paper was applied at the growing colony edge. The cultures continued to incubate up to 2 more weeks (Pratt 2006).

For preparations of conidia for use in bioassays, conidia were suspended in sterile purified water. To prepare suspensions of
Fusarium conidia, a small volume of sterile purified water was applied to the surface of the $\mathrm{KCl}$ medium, the spores and mycelium were gently dislodged, and the suspension was retrieved by pipetting. To prepare suspensions of Alternaria or Cochliobolus conidia for use in bioassays, filter paper was aseptically transferred to microcentrifuge tubes, sterile purified water was added, then the suspension was vortexed briefly to dislodge the conidia.

To prepare conidial suspensions for long-term storage of fungi, isolates of the 3 genera were grown as described above to induce production of conidia. For Alternaria and Curvularia isolates, the filter paper was aseptically transferred to microcentrifuge tubes with $2 \mathrm{~mL}$ of sterile skim milk (BD) and vortexed as above. For Fusarium isolates, $1 \mathrm{~mL}$ of sterile skim milk was applied to the $\mathrm{KCl}$ culture, and a conidial suspension was obtained as above. Conidial suspensions were maintained on ice throughout the process of preparing fungi for long-term storage. For all 3 genera, $300 \mu \mathrm{L}$ of each conidial suspension was evenly distributed over precooled sterile silica gel ( $3 \mathrm{~mL}$ vol in $15 \mathrm{~mL}$ screw cap tubes) (Grace Davison, Columbia, Maryland) (Windels et al. 1988). Another $300 \mu \mathrm{L}$ of each conidial suspension was added to an equal volume of $80 \%$ glycerol in cryovials. Finally, each suspension was aseptically streaked onto PDA slants, using a loop, and allowed to grow 3-5 days at room temperature. The slant cultures and freshly prepared silica gel stocks were stored at $4{ }^{\circ} \mathrm{C}$ while the glycerol stocks were stored at $-80{ }^{\circ} \mathrm{C}$.

\section{Semiselective media}

Semiselective media tested were as follows. DRBC agar medium, a general purpose fungal medium, was prepared with $0.5 \%$ $(\mathrm{m} / \mathrm{v})$ peptone, $1.0 \%(\mathrm{~m} / \mathrm{v})$ glucose, $7 \mathrm{mmol} / \mathrm{L}$ potassium phosphate, monobasic, $2 \mathrm{mmol} / \mathrm{L}$ magnesium sulfate, heptahydrate, $1.5 \%(\mathrm{~m} / \mathrm{v})$ agar, with the following added to the warm, sterilized solution, 10 $\mu \mathrm{mol} / \mathrm{L}$ dichloran (SA), $25 \mu \mathrm{mol} / \mathrm{L}$ rose bengal (SA), and $300 \mu \mathrm{mol} / \mathrm{L}$ chloramphenicol (SA), each added in solution prepared in either ethanol (dichloran and chloramphenicol) or sterile purified water (rose bengal). A medium made with the nonionic surfactant Tergitol-7 (nonylphenol ethoxylate), previously used in selective medium for Cochliobolus spp. (Yang 1973), was prepared by amending Tergitol-7 agar (Fluka BioChemika, Buchs, Switzerland) with 0.011\% $(\mathrm{m} / \mathrm{v})$ PCNB; $700 \mu \mathrm{mol} / \mathrm{L}$ streptomycin sulfate (Fisher BioReagents, Fair Lawn, New Jersey, USA) was added to the warm, sterilized medium (designated as Ter). A V8-juice-based agar medium, amended with nalidixic acid and chlortetracycline (V8+), useful for isolating fungi from environmental samples, was prepared as previously described (Wilson 2002). Also prepared was a modification of this medium (ModV8) that had reduced quantities of antimicrobials. It contained $20 \%(v / v)$ V8 juice (Campbell Soup Co., Camden, New Jersey), $30 \mathrm{mmol} / \mathrm{L}$ calcium carbonate, $2.0 \%(\mathrm{~m} / \mathrm{v})$ agar, which is then autoclaved, and to this warm, sterilized solution, $1.0 \mathrm{mmol} / \mathrm{L}$ nalidixic acid (SA) and $500 \mu \mathrm{mol} / \mathrm{L}$ chlortetracycline hydrochloride (SA) are added. Nalidixic acid was added in a filter-sterilized (Millex-GV $0.22 \mu \mathrm{mol} / \mathrm{L}$ filter unit, Millipore S.A., Molsheim, France) solution prepared with $100 \mathrm{mmol} / \mathrm{L}$ nalidixic acid (SA) and $100 \mathrm{mmol} / \mathrm{L}$ sodium hydroxide in sterile purified water. Also utilized in this study were DCPA and PCNB, which have been commonly used for screening for Fusarium and Alternaria spp. from sorghum (Andrews and Pitt 1986; Nash and Snyder 1962).

\section{Media for morphological characterization of Alternaria and Cochliobolus spp.}

The following media were used for morphological characterization of Alternaria isolates (Dugan and Peever 2002; Simmons 2007):V8 juice agar (lacking amendments) (V8), one-half-strength V8 juice agar (also lacking amendments), full-strength PDA (lacking ampicillin), malt extract agar (MEA; prepared from malt extract broth (BD)), dichloran rose bengal yeast extract sucrose agar (DRYES), and potato carrot agar (PCA) (HiMedia Laboratories, 
Pvt. Ltd., Mumbai, India). DRYES consisted of $2 \%$ yeast extract, $15 \%$ sucrose, and $2 \%$ agar amended with $10 \mu \mathrm{mol} / \mathrm{L}$ dichloran, $25 \mu \mathrm{mol} / \mathrm{L}$ rose bengal, and $300 \mu \mathrm{mol} / \mathrm{L}$ chloramphenicol. For morphological identification of Cochliobolus isolates, V8 and water agar were used.

\section{Selection of Cochliobolus, Alternaria, and Fusarium on different media}

Testing of semiselective media for growth of $\mathrm{C}$. lunata, Alternaria sp., and F. thapsinum colonies

To determine which media among 4 would be potentially useful for isolation of fungi from sorghum tissues, a preliminary screen of different media, for growth and selectivity of representative species from Cochliobolus, Alternaria, and Fusarium, was conducted. The media to be tested were Ter, $\mathrm{DRBC}, \mathrm{V8}^{+}$, and ModV8; CMA was also included since the 3 fungi grew well upon this medium. Agar media were prepared in $100 \mathrm{~mm}$ Petri dishes. Fungal species commonly isolated from sorghum grain were grown for production of conidia. To represent a common Fusarium grain pathogen, isolate M-3790 (Fusarium Research Center, Pennsylvania State University, University Park, Pennsylvania), which was identified morphologically (Klittich et al. 1997) and molecularly (Funnell-Harris and Pedersen 2008) as F. thapsinum (teleomorph G. thapsina), was used. Throughout the manuscript, this isolate will be known by the more familiar F. thapsinum. Alternaria sp. grain isolate H02781S-3b, which was isolated at Lincoln, Nebraska (Funnell-Harris and Pedersen 2008), was used to represent Alternaria spp. To represent Cochliobolus isolates, LP09-1, which was previously identified morphologically as C. lunata (Little and Magill 2003) (teleomorph Co. lunatus), was used.

Conidia of each fungus were produced as described above. Conidial suspensions were prepared in sterile purified water, quantified using a haemocytometer, and diluted to $5 \times 10^{3}$ conidia/ $\mathrm{mL} ; 150 \mu \mathrm{L}$ was spread onto each medium. Conidial suspensions of each fungus and a conidial mixture of C. lunata, F. thapsinum, and Alternaria sp. (2:1:1) were prepared. Three plates per treatment were inoculated and Petri dishes were incubated at $25{ }^{\circ} \mathrm{C}$ in the dark for 5-6 days. Number of colonies and range of colony diameters were determined for each plate; the mean of each range was calculated.

The experimental design was completely randomized and each treatment combination was replicated 3 times. The experiment was conducted twice. Data were analyzed using the PROC MIXED procedure of SAS/STAT software (SAS 2002-2008). Repetitions of the experiment and replications of treatment combinations within experiment repetitions were considered random effects. Media and inoculum were considered fixed. The model was factorial including all interactions. The KENWARD-ROGER option was specified for estimating degrees of freedom. Least squares means were generated and differences among treatment main-effect least squares means, and among least squares means of treatment combinations were compared using the DIFF option.

Since this was a preliminary screen, the results are summarized here (data not shown). For C. lunata, the greatest amount of growth on semiselective media was observed on ModV8 medium. When inoculated with Alternaria sp. conidia, the mean colony diameters on DRBC and ModV8 were greater than on other semiselective media. For inoculation with $F$. thapsinum conidia, growth on ModV8, $\mathrm{V}^{+}$, and DRBC was similar $(P \geq 0.07)$.

To determine the ability to distinguish $C$. lunata from the other 2 fungi on the different semiselective media, putative $C$. lunata colonies were transferred from each medium onto half-strength PDA for colony identification. Transferred colonies from all media grew on PDA in the first assay; during the second assay, only 50\% of colonies transferred from Ter grew on PDA. Curvularia lunata colonies could be readily distinguished on CMA, DRBC, ModV8, or
$\mathrm{V}^{+}$and less so on Ter. Upon assessing these results, DRBC and ModV8 were chosen for further analyses.

\section{Radial growth bioassays}

Radial growth bioassays were performed using the $F$. thapsinum, Alternaria sp. and $C$. lunata isolates described above. Two experiments were conducted. Since it previously was demonstrated that mycelium is apparent in mature grain following artificial infection of sorghum heads with F. thapsinum (Little et al. 2012), one experiment was designed using mycelial mats as starting inoculum. To account for the possibility of relatively few viable fungal cells remaining in mature grain, a second experiment was designed with single germinated conidia, or hyphal tips from single germinated conidia as starting inoculum.

For the first experiment with mycelial mats as starting inoculum, growth rates were determined on 5 media: half-strength PDA (lacking amendments), DCPA, PCNB, DRBC and ModV8. Mycelium was prepared in the following way. A spore suspension was spread onto half-strength PDA (lacking amendments) then incubated 2-3 days in a moist chamber at $28{ }^{\circ} \mathrm{C}$. At that time a layer of mycelia covered the medium in each plate. A number 2 cork-borer (radius $3 \mathrm{~mm}$ ) was used to cut agar disks from each inoculum plate. One agar disk was placed on the edge of each medium, prepared in $35 \mathrm{~mm}$ Petri dishes. Three plates per treatment were prepared. The plates were incubated in a moist chamber at $28{ }^{\circ} \mathrm{C}$. Measurements of radial distance from the edge of the disk nearest the center of the medium were taken daily for 4 days, using a dissecting microscope.

The experimental design was completely randomized and each treatment combination was replicated 3 times. The experiment was conducted 3 times. Data were analyzed using the PROC MIXED procedure of SAS/STAT software (SAS 2002-2008). Each inoculum was analyzed separately. Repetitions of the experiment were considered random effects. Media were considered fixed effects. Measurements across time on the same plate were considered repeated measures. The KENWARD-ROGER option was specified for estimating degrees of freedom. Slopes were output using the SOLUTION option and the NOINT option was used to force the intercept to zero at the initiation of the experiment. Confidence intervals for the slopes were set at $P=0.05$ using the CL option. Comparisons among media were made using single degree of freedom contrasts.

Radial growth bioassays also were performed to determine the growth rates of F. thapsinum, Alternaria sp., C. lunata and 2 other Cochliobolus isolates (H05-531S-2 and H05-557S-1), from either hyphal tips or germinated single conidia on 3 media: PDA (lacking amendments), ModV8 and DRBC. Conidial suspensions from each fungus were prepared in sterile purified water and spread onto half-strength PDA amended with $200 \mu \mathrm{mol} / \mathrm{L}$ ampicillin (SA) prepared in $100 \mathrm{~mm}$ Petri dishes; plates were incubated 16 to $20 \mathrm{~h}$ at $25^{\circ} \mathrm{C}$. Agar blocks no larger than $1 \mathrm{~mm}^{3}$, each containing a germinated conidium or a hyphal tip from a germinated conidium, were aseptically cut from the PDA cultures and placed at the edge of media prepared in $35 \mathrm{~mm}$ Petri dishes. Five plates per treatment were prepared and incubated in a moist chamber at $25^{\circ} \mathrm{C}$. Survival on each medium was indicated by the presence of growth, as determined using a dissecting microscope, on each of 5 plates. Measurements of radial distance from the edge of the block closest to the center of the plate were taken daily for 4 days, also using a dissecting microscope.

The experimental design was completely randomized and each treatment combination was replicated 5 times. The experiment was conducted 3 times. Data were analyzed using the PROC MIXED procedure of SAS/STAT software (SAS 2002-2008). Each inoculum was analyzed separately. Repetitions of the experiment were considered random effects. The model used to analyze the spore survival data included media as its single fixed factor. The KENWARD-ROGER option was specified for estimating degrees of 
freedom. Least squares means were generated, and the differences among media least squares means were compared using the DIFF option. Media was considered a fixed effect in the model used to analyze radial growth, and measurements across time on the same plate were considered repeated measures. The KENWARDROGER option was specified for estimating degrees of freedom. Slopes were output using the SOLUTION option and the NOINT option was used to force the intercept to zero at the initiation of the experiment. Confidence intervals for the slopes were set at $P=0.05$ using the CL option. Comparisons among media were made using single degree of freedom contrasts.

The data were reanalyzed to compare growth of the 5 fungi on PDA to determine whether isolates grew at similar rates on this medium. The model used for this analysis considered repetitions of the experiment to be random effects. Fungal isolates were considered fixed effects. Measurements across time on the same plate were considered repeated measures. The KENWARD-ROGER option was specified for estimating degrees of freedom. Slopes were output using the SOLUTION option and the NOINT option was used to force the intercept to zero at the initiation of the experiment. Confidence intervals for the slopes were set at $P=0.05$ using the CL option. Comparisons among fungal inoculums were made using single degree of freedom contrasts.

Isolation of Cochliobolus, Alternaria, and Fusarium spp. from field-grown grain using semiselective media

The media ModV8, DRBC, PCNB, and DCPA were used to screen for Cochliobolus, Alternaria, and Fusarium spp. from field-grown grain. Sorghum was planted at Ithaca and Lincoln, Nebraska, in 2005, and at Corpus Christi, Texas, in 2008. For details of sorghum lines planted see Pedersen and Toy (2001) (Pedersen and Toy 2001). Plots consisted of two $7.6 \mathrm{~m}$ rows spaced $0.76 \mathrm{~m}$ apart at Ithaca and Lincoln and of two $5.2 \mathrm{~m}$ rows spaced $1.0 \mathrm{~m}$ apart at Corpus Christi. Plots at Ithaca were irrigated with overhead sprinklers, 5 times through the growing season, $3.8 \mathrm{~cm}$ per application. Plots at Lincoln and Corpus Christi were not irrigated. The field experimental design at all environments was a randomized complete block with 4 replications.

At grain maturity, 5 randomly chosen heads were removed from each plot, dried, then the mature seeds were threshed and the chaff was removed. Surface infection of mature grain was not apparent. Therefore, to screen for internal infections, probably due to infections of flowers or developing grain, grain was surface sterilized to remove incidental spores or mycelium. Grain from each field plot was washed for $2 \mathrm{~min}$ in $95 \%$ ethanol followed by a $10 \mathrm{~min}$ wash in $1 \%$ sodium hypochlorite with $0.01 \%$ Tween 20 , rinsed 3 times in sterile purified water then dried in a laminar-flow hood. Five seeds were aseptically applied to each medium. There were 4 replicate plots of each line, and 10 lines, thus, 200 seeds per location, or 600 total seeds were screened per medium.

Individual colonies growing from each seed onto the medium were transferred to PDA. After a preliminary identification to genus, transfers were made to the appropriate media for inducing sporulation, as described above. For preliminary identification, Simmons $(1967,1990,1999)$ and Simmons and Roberts (1993) were utilized for Alternaria isolates, Barnett and Hunter (1972) and Ellis (1971) were utilized for Cochliobolus isolates, and Leslie and Summerell (2006) and Nelson et al. (1983) were utilized for Fusarium spp. (Barnett and Hunter 1972; Ellis 1971; Leslie and Summerell 2006; Nelson et al. 1983; Simmons 1967, 1990, 1999; Simmons and Roberts 1993). Colony morphology on PDA and conidiophore structures and conidial types were initially used for identification. Fungi per 100 seeds were enumerated for each medium. Groups analyzed were Cochliobolus, Alternaria, Fusarium, and other fungi ("Other").

The experimental design at each location was a randomized complete block with 4 replications. Data were analyzed using the PROC MIXED procedure of SAS/STAT software (SAS 2002-2008).
Each fungal group was analyzed separately. Location and replications within location were considered random effects. The model used to analyze fungal numbers included media as its single fixed factor. The KENWARD-ROGER option was specified for estimating degrees of freedom. Least squares means were generated, and differences among media least squares means were compared using the DIFF option.

\section{Inoculation of seedlings with conidia of $C$. lunata, Alternaria sp., F. thapsinum, or a mixture of the 3 species}

Previous studies had utilized DCPA for root isolations because PCNB medium had been considered too harsh when applied with some plant tissues (Funnell-Harris and Pedersen 2008; D.L. Funnell-Harris and J.F. Pedersen, unpublished). The purpose of the present assay was to test 2 media, DRBC and ModV8, for ability to recover $C$. lunata, Alternaria sp., and F. thapsinum from infected root tissues. This assay also allowed assessment of competition of the 3 fungi in the root zone of sorghum, under conditions of the assay, by using mixed inoculations.

Seedlings of sorghum 'RTx430' were grown with slight modifications in Magenta boxes with plant growth medium (FunnellHarris and Pedersen 2008). Briefly, greenhouse-grown seeds were surface sterilized and germinated on $0.6 \%$ water agar in a growth chamber for $5-7$ days at $25{ }^{\circ} \mathrm{C}, 16 \mathrm{~h}$ light. Germinated seeds were transferred to Magenta boxes prepared with Murashige and Skoog basal growth medium with Gamborg's vitamins (MP Biomedicals, LLC, Solon, Ohio) modified for sorghum plant culture (FunnellHarris and Pedersen 2008). Seedlings were returned to the growth chamber and grown for 8 more days with the same temperature and light regime. Conidial suspensions of each fungus, C. lunata, Alternaria sp., and F. thapsinum, and of a mixture of C. lunata, Alternaria sp., and F. thapsinum (1:1:1) were prepared in sterile purified water as described above, and $1.25 \times 10^{3}$ conidia were applied at the base of the stalk of each seedling. Control plants were inoculated with sterile purified water. Plants were arranged in a growth chamber in 9 or 11 blocks, each block with 5 treatments. The seedlings were grown at $22{ }^{\circ} \mathrm{C}, 12 \mathrm{~h}$ light, for $15-21$ days and then scored. Percent discoloration of roots or shoots, shoot weight, and stalk lesion length were recorded. Percent root infection was determined by plating $1 \mathrm{~cm}$ lengths of roots onto 2 media, DRBC and ModV8. After incubation at room temperature, the root pieces were scored 28-42 $\mathrm{h}$ after plating, using a dissecting microscope. At $42 \mathrm{~h}$ after plating, from infected root pieces resulting from mixed inoculation of the 3 fungal species, colonies were transferred onto half-strength PDA using a dissecting microscope to discern small colonies. The PDA plates were incubated at room temperature, and 5-7 days later the fungal species were identified to determine recovery of fungi from infected roots from each semiselective medium. The entire experiment was conducted 2 times.

The experimental design for each repetition of the experiment was a randomized complete block with 9 replications in 1 repetition, and 11 replications in the other repetition of the experiment. Data were analyzed using the PROC MIXED procedure of SAS/STAT software (SAS 2002-2008). Repetition, replications within repetitions, and position of samples within replications were considered random effects. The model included inoculum as its single fixed factor. The KENWARD-ROGER option was specified for estimating degrees of freedom. Least squares means were generated, and differences among least squares means were compared using the DIFF option. Pearson correlations were generated for all response variables using SAS Proc Corr software (SAS 2002-2008). Chi-square tests for differences in percent root infection attributable to DRBC and ModV8 media were made using SAS Proc Freq software (SAS 2002-2008). 


\section{Morphological identification of Alternaria and Cochliobolus spp.}

Identification of Alternaria spp. by characteristics when grown on different media was conducted as described by Dugan and Peever (Dugan and Peever 2002; Simmons 2007). The agar media, V8, half-strength V8, full-strength PDA, MEA, DRYES, and PCA, were prepared in $60 \mathrm{~mm}$ Petri dishes. Nine sorghum grain isolates (CC06-61S-2, H02-747S-5, H02-755S, H02-781S-3b, M05-1541S-1 (ModV8), M05-1551S-4 (DCPA), M05-1551S-4 (ModV8), M05-1553S-3b (DCPA), M05-1561S-5 (DRBC)), representing differing morphological types when grown on half-strength PDA and water agar, were transferred from half-strength PDA by point inoculation to each medium. Cultures were incubated at $22{ }^{\circ} \mathrm{C}, 8 \mathrm{~h}$ light, $33 \mathrm{~cm}$ from fluorescent lamps (daylight conditions). Duplicate DRYES plates were incubated at $25^{\circ} \mathrm{C}$, in darkness. Morphological descriptions of V8, half-strength V8, full-strength PDA, MEA, and DRYES cultures were recorded 4-17 days after inoculation, depending on isolate; light- and dark-grown DRYES cultures were scored the same day for a given isolate. PCA cultures were scored 6-18 days after inoculation. Conidial and conidiophore morphologies, as well as colony morphology, were recorded. Dimensions of 45-71 conidia, taken from 3-5 PCA plates per isolate, were determined, and means and standard deviations of length and width were calculated. For 3 isolates, conidiation on PCA medium was poor, and due to mycelial growth, conidiophore morphology was difficult to distinguish. Therefore, these isolates were also grown on water agar with filter paper, using daylight conditions 18-25 days to determine conidiophore morphology. Using colony, conidia and conidiophore morphologies, and mean conidia dimensions, Alternaria isolates were placed into morphologically similar groups.

Morphologically based identification of 4 Cochliobolus isolates, representing different morphological types on half-strength PDA and CMA, was conducted in this way. Transfers were made by point inoculation to V8 medium and cultures were grown 5 days, $33 \mathrm{~cm}$ under $8 \mathrm{~h}$ of fluorescent light at $22{ }^{\circ} \mathrm{C}$. Agar blocks were aseptically cut and transferred to water agar; plates were incubated in the same way 7-11 days before scoring morphologies of conidia and conidiophores and determining conidia dimensions. Species identifications were made in accordance with Sivanesan (1987).

\section{Molecular analysis of Cochliobolus and Alternaria spp. from sorghum grain}

DNA sequences from 3 loci for Cochliobolus and 4 loci for Alternaria isolates from sorghum grain were analyzed. DNA was extracted, as previously described (Lee and Taylor 1990), from lyophilized mycelia grown in full-strength potato dextrose broth. The internal transcribed spacer (ITS) region was amplified using ITS5 and ITS4 primers and conditions as previously described (O’Donnell et al. 1998; White et al. 1990). A region in the mitochondrial small subunit of the rRNA gene (mt SSU) was amplified using primers NMS1 and NMS2, also as previously described (Li et al. 1994). A portion of the glyceraldehyde-3-phosphate dehydrogenase gene (gpd) was amplified using primers gpd1 and gpd2 (Berbee et al. 1999). A $50 \mu \mathrm{L}$ volume reaction was prepared with $1.5 \mathrm{mmol} / \mathrm{L}$ $\mathrm{MgCl}_{2}, 400 \mu \mathrm{mol} / \mathrm{L} \mathrm{dNTPs}, 20 \mathrm{pmol}$ of each primer, 2.5 units of Amplitaq Gold (Applied Biosystems, Life Technologies Corporation, Carlsbad, California), and $1 \times$ buffer. Reactions were incubated at $96{ }^{\circ} \mathrm{C}$ for $2 \mathrm{~min}$, then there were 40 cycles of $96{ }^{\circ} \mathrm{C}$ for $1 \mathrm{~min}, 48^{\circ} \mathrm{C}$ for $1 \mathrm{~min}$, and $72{ }^{\circ} \mathrm{C}$ for $45 \mathrm{~s}$ for the first cycle with a $3 \mathrm{~s}$ increase per cycle thereafter, followed by a final extension at $72{ }^{\circ} \mathrm{C}$ for $7 \mathrm{~min}$. For amplifications of these loci, products of the expected sizes were purified using Amicon Ultra-0.5 Centrifugal Filter Device (Millipore, Billerica, Massachusetts). Occasionally, multiple products resulted; in these cases, bands of the expected size were gel-purified using the E.Z.N.A. Ultra-Sep Gel Extraction kit (Omega bio-tek, Norcross, Georgia).
Amplification of the endo-polygalacturonase gene (endo-PG) from Alternaria spp. isolates was conducted using the reaction mixture described above with primers PG2 and PG3 (Peever et al. 2002). The amplification conditions were $5 \mathrm{~min}$ of incubation at $95{ }^{\circ} \mathrm{C}$, then 50 cycles of $95{ }^{\circ} \mathrm{C}$ for $1 \mathrm{~min}, 50{ }^{\circ} \mathrm{C}$ for $1 \mathrm{~min}$, and $72{ }^{\circ} \mathrm{C}$ for $1 \mathrm{~min}$, followed by a final extension at $72{ }^{\circ} \mathrm{C}$ for $7 \mathrm{~min}$. All products of the appropriate size (Peever et al. 2002) were gelpurified as described above. In most cases, reamplification of PCR products was conducted to obtain adequate product for sequencing, using the conditions just described with $0.5-2.0 \mu \mathrm{L}$ of the gel-purified eluent and reducing the cycles to 25. Products of reamplification were gel-purified.

Sequencing of purified PCR amplification products was conducted using primers used for amplification. For ITS, gpd, and $\mathrm{mt}$ SSU, both primers were utilized and sequences from opposite strands were assembled using Sequencher 4.10.1 (Gene Codes Corp., Ann Arbor, Michigan, USA). Assembled sequences were compared with those in the nucleotide collection in GenBank using megablast, and submitted to GenBank (Table 1). In the case of endo-PG, only the $5^{\prime}$ primer (PG3) was used for sequencing. Sequences were trimmed as needed and compared with those in GenBank. In addition to Cochliobolus spp. listed in Table 1, sequences of ITS regions from 16 additional Cochliobolus isolates also were determined and submitted to GenBank (accession Nos. JX960581-JX960596).

Primers were purchased from Life Technologies (Grand Island, New York) and Bioneer (Alameda, California). Sequencing was conducted at Eton Bioscience, Inc. (San Diego, California) and University of Arkansas for Medical Sciences (Little Rock).

\section{Results}

Radial growth of C. lunata, Alternaria sp., and F. thapsinum on semiselective media

Relative growth rates (mm/day) of C. lunata, Alternaria sp., and F. thapsinum from disks of mycelia on the media DRBC and ModV8 were compared with those on PDA, DCPA, and PCNB. There were significant effects of medium on growth of each fungal isolate $(P<0.01)$. For all 3 fungi, growth on ModV8 was faster than on DRBC $(P<0.01)$ (Table 2). Relative growth rates of $C$. lunata, F. thapsinum, and Alternaria sp., and 2 additional Cochliobolus sp. isolates, starting from a single germinated conidium or the hyphal tip of a germinated conidium, on ModV8, DRBC, and PDA, were also compared. There were significant effects of medium on growth of C. lunata, and one other Cochliobolus isolate (H05-557S-1) $(P<0.01)$. In this assay, when inoculum was relatively small, all Cochliobolus isolates and the Alternaria sp. isolate grew faster on DRBC than ModV8 (Table 3A). There were no significant effects of medium on survival of single germinated spores or hyphal tips $(P \geq 0.24)$ (Table 3B). Percent survival was consistently lower on ModV8, but the differences were not significant in pairwise comparisons $(P \geq 0.27)$. Additionally, there were no significant differences in growth rates of the different fungi on PDA medium $(P=0.61)$

\section{Isolation of Cochliobolus, Alternaria, and Fusarium spp. from} field-grown grain using 4 semiselective media

Grain grown at 3 environments were screened on 4 semiselective media (DRBC, ModV8, DCPA, and PCNB). Fungal colonies growing from the grain and onto each medium were collected, and the numbers of Cochliobolus, Alternaria, and Fusarium spp., as well as other fungi, were enumerated. Medium had a significant effect on numbers of colonies collected in each fungal category $(P \leq 0.01)$ (Table 4). Selection on DRBC and ModV8 resulted in the greatest number of Cochliobolus, Alternaria, and Fusarium isolates, and both media yielded significantly more Fusarium spp. colonies per 100 grains than did PCNB. DRBC and ModV8 did not allow significantly more growth of other fungi than DCPA, another 
Table 1. Representative Alternaria and Cochliobolus isolates from sorghum grain, characterized morphologically and molecularly in this study.

\begin{tabular}{|c|c|c|c|}
\hline Isolate No. & Medium* & Environment $^{\dagger}$ & GenBank acc. No. \\
\hline \multicolumn{4}{|l|}{ Alternaria } \\
\hline H02-711S-2 & DCPA & Lincoln, Nebraska, 2002 & $\begin{array}{l}\text { JX960578, ITS } \\
\text { EF152429, mt SSU } \\
\text { JX960574, gpd }\end{array}$ \\
\hline H02-747S-5 & DCPA & Lincoln, Nebraska, 2002 & $\begin{array}{l}\text { JX960576, ITS } \\
\text { EF152432, mt SSU }\end{array}$ \\
\hline H02-781S-3b & DCPA & Lincoln, Nebraska, 2002 & $\begin{array}{l}\text { JX960577, ITS } \\
\text { EF152430, NMS } \\
\text { JX960575, gpd }\end{array}$ \\
\hline M05-1541S-1 & Mod V8 & Ithaca, Nebraska, 2005 & $\begin{array}{l}\text { JN634835, ITS } \\
\text { JN634842, mt SSU } \\
\text { JN634821, gpd }\end{array}$ \\
\hline M05-1551S-4 & DCPA & Ithaca, Nebraska, 2005 & $\begin{array}{l}\text { JN634833, ITS } \\
\text { JN634840, mt SSU } \\
\text { JN634819, gpd }\end{array}$ \\
\hline M05-1551S-4 & ModV8 & Ithaca, Nebraska, 2005 & $\begin{array}{l}\text { JX960579, ITS } \\
\text { JN634843, mt SSU } \\
\text { JN634822, gpd }\end{array}$ \\
\hline M05-1553S-3b & DCPA & Ithaca, Nebraska, 2005 & $\begin{array}{l}\text { JN634834, ITS } \\
\text { JN634841, mt SSU } \\
\text { JN634820, gpd }\end{array}$ \\
\hline M05-1561S-5 & DRBC & Ithaca, Nebraska, 2005 & $\begin{array}{l}\text { JN634836, ITS } \\
\text { JN634844, mt SSU } \\
\text { JN634823, gpd }\end{array}$ \\
\hline M05-1557S-4 & ModV8 & Ithaca, Nebraska, 2005 & $\begin{array}{l}\text { JN634837, ITS } \\
\text { JN634845, mt SSU } \\
\text { JN634824, gpd }\end{array}$ \\
\hline \multicolumn{4}{|l|}{ Cochliobolus } \\
\hline & DRBC & Lincoln, Nebraska, 2005 & $\begin{array}{l}\text { JN700926, ITS } \\
\text { JN634827, gpd }\end{array}$ \\
\hline H05-531S-2 & DRBC & Lincoln, Nebraska, 2005 & $\begin{array}{l}\text { JN634839, ITS } \\
\text { JN634847, mt SSU } \\
\text { JN634826, gpd }\end{array}$ \\
\hline H05-557S-1 & ModV8 & Lincoln, Nebraska, 2005 & $\begin{array}{l}\text { JX960580, ITS } \\
\text { JN634848, mt SSU } \\
\text { JN634828, gpd }\end{array}$ \\
\hline LP09-1§ & & & $\begin{array}{l}\text { JN634838, ITS } \\
\text { JN634846, mt SSU } \\
\text { JN634825, gpd }\end{array}$ \\
\hline
\end{tabular}

*Semiselective media used to isolate Alternaria and Cochliobolus spp. from sorghum grain were dichloran chloramphenicol peptone agar (DCPA), dichloran rose bengal chloramphenicol agar (DRBC), and modified V8 agar medium containing nalidixic acid and chlortetracycline (ModV8).

+"Environment" is the location and year grain was grown from which fungal isolate came.

¥Accession numbers for sequences from the internal transcribed spacer region from rDNA (ITS), mitochondrial small subunit of the rDNA region (mt SSU), and a portion of the glyceraldehyde-3-phosphate dehydrogenase gene (gpd).

§For details about isolate see Little and Magill (2003).

medium used for isolation of Fusarium and Alternaria spp. (Table 4).

Inoculation of seedlings with conidia of $C$. lunata, Alternaria sp., and $F$. thapsinum and isolation of these fungi from roots

Following inoculation of seedlings with conidia of $C$. lunata, Alternaria sp., or F. thapsinum, with a mixture of the 3 fungi (1:1:1), or with sterile water, percent fungal recovery from roots were determined by excising root pieces from each plant and plating them onto DRBC and ModV8 agar. Isolation of fungi from roots was highly correlated for the 2 media $\left(r^{2}=0.84 ; P<0.01\right)$. Means and standard errors for each measurement are shown in Table 5. Treatment was significant for all measurements $(P<0.01)$. Inoculations of sorghum seedlings with Alternaria sp. and F. thapsinum conidia significantly increased root and shoot discoloration, shoot lesion length, and percent recovery from roots, as deter-
Table 2. Slopes (radial growth (mm)/day) resulting from regression analyses of radial growth bioassays of sorghum grain fungi grown on different media.

\begin{tabular}{llcl}
\hline Medium* & $\begin{array}{l}\text { Curvularia } \\
\text { lunata }\end{array}$ & Alternaria sp. & $\begin{array}{l}\text { Fusarium } \\
\text { thapsinum }\end{array}$ \\
\hline PDA & $6.78 \mathrm{a} \pm 0.40$ & $5.11 \mathrm{a} \pm 0.36$ & $2.66 \mathrm{a} \pm 0.39$ \\
ModV8 & $5.02 \mathrm{~b} \pm 0.40$ & $4.03 \mathrm{~b} \pm 0.36$ & $5.04 \mathrm{~b} \pm 0.39$ \\
DCPA & $4.84 \mathrm{~b} \pm 0.40$ & $3.46 \mathrm{c} \pm 0.36$ & $5.09 \mathrm{~b} \pm 0.39$ \\
DRBC & $3.93 \mathrm{c} \pm 0.40$ & $3.15 \mathrm{c} \pm 0.36$ & $4.32 \mathrm{c} \pm 0.39$ \\
PCNB & $0.64 \mathrm{~d} \pm 0.17$ & $0.60 \mathrm{~d} \pm 0.15$ & $2.20 \mathrm{~d} \pm 0.16$ \\
\hline
\end{tabular}

Note: Slopes calculated from estimates for fixed effects, and standard errors, are reported. For a given fungus, slopes with different letters are significantly different at $P \leq 0.05$.

*PDA is half-strength potato-dextrose, commonly used for growing fungi; ModV8 is a modification of a V8-juice-based agar (see Materials and methods); DCPA (dichloran chloramphencial peptone agar) is a semiselective medium for Fusarium spp. and Alternaria spp. and other dark-spored ascomycetes (Andrews and Pitt 1986); DRBC (dichloran rose bengal chloramphenicol) is another commonly used medium for selection of fungi; PCNB (pentachloronitrobenzene) is semiselective for Fusarium spp. (Nash and Snyder 1962).

mined on both media, and decreased shoot mass, as compared with the water control $(P<0.01)$, similar to what has been previously observed (Funnell-Harris and Pedersen 2008). When seedlings were inoculated with $C$. lunata conidia, all measurements were significantly different from the water control $(P \leq 0.03)$. For lesion length and percent shoot discoloration, measurements were significantly less on plants inoculated with $C$. lunata conidia than on those inoculated with $F$. thapsinum conidia $(P<0.01)$. Mean shoot mass of plants inoculated with $C$. lunata was significantly greater than of plants inoculated with Alternaria sp. or F. thapsinum conidia $(P \leq 0.02)$ (Table 5). Inoculation of seedlings with $C$. lunata conidia resulted in percent root discoloration similar to that following inoculation with $F$. thapsinum $(P=0.19)$ and significantly less than that resulting from inoculation with Alternaria sp. conidia $(P<0.01)$. However, mean percent $C$. lunata recovery from roots, as determined on 2 media, was significantly greater than that following inoculation with $F$. thapsinum conidia $(P<0.01)$ and similar to that resulting from inoculation with Alternaria $(P \geq 0.10)$.

When a mixture of conidia from the 3 fungal species was inoculated onto seedlings, the responses were similar to those obtained when F. thapsinum alone was inoculated onto seedlings, especially when considering measurements for mean shoot mass, lesion length, and percent fungal recovery from roots as determined on both media $(P \geq 0.14)$ (Table 5). Fusarium thapsinum was most frequently recovered (62\%) from infected roots resulting from inoculations with conidial mixtures, and a few C. lunata colonies (7\%) were recovered from DRBC and ModV8 plates while only $1 \%$ of the reisolated colonies were Alternaria sp. Thirty-one percent of colonies transferred from the semiselective media did not grow. This rate of recovery may have been due to transfer of very small colonies that may have been damaged in the process; transfer from larger single colonies from these media to PDA did not result in loss of viability (see Materials and methods). Chisquare analyses of $F$. thapsinum and $C$. lunata transferred colonies and attempted transfers that did not grow indicated that there were no significant differences between the 2 media $(P \geq 0.32)$.

\section{Morphological and molecular analyses of representative Alternaria isolates from sorghum grain}

Representative Alternaria spp. isolates obtained from sorghum grain were identified morphologically using the system described by Dugan and Peever (Dugan and Peever 2002). Colony, conidia, and conidiophore morphologies were compared by growing each isolate on 6 media. Isolates were compared with descriptions of species complexes commonly found on grain. Three isolates (H02747S-5, M05-1553S-3b, and M05-1541S-1) had characteristics that placed them in the Alternaria alternata species complex, particu- 
Table 3. (A) Slopes (radial growth $(\mathrm{mm}) /$ day) resulting from regression analyses of radial growth bioassays; and (B) percent survival of sorghum grain fungi grown from germinated single spores or hyphal tips on different media.

\begin{tabular}{|c|c|c|c|c|c|}
\hline \multirow[b]{2}{*}{ Medium* } & \multirow[b]{2}{*}{$\begin{array}{l}\text { Curvularia } \\
\text { lunata }\end{array}$} & \multicolumn{2}{|c|}{ Cochliobolus sp. } & \multirow[b]{2}{*}{ Alternaria sp. } & \multirow[b]{2}{*}{$\begin{array}{l}\text { Fusarium } \\
\text { thapsinum }\end{array}$} \\
\hline & & $\begin{array}{l}\text { Isolate } \\
\text { H05-557S-1 }\end{array}$ & $\begin{array}{l}\text { Isolate } \\
\text { H05-531S-2 }\end{array}$ & & \\
\hline \multicolumn{6}{|c|}{ (A) Slopes ${ }^{\dagger}$} \\
\hline PDA & $7.30 \mathrm{a} \pm 0.13$ & $6.86 a \pm 0.16$ & $5.70 \mathrm{a} \pm 0.24$ & $5.04 a \pm 0.15$ & $4.31 \mathrm{a} \pm 0.21$ \\
\hline DRBC & $1.63 b \pm 0.31$ & $1.54 \mathrm{~b} \pm 0.36$ & $1.69 b \pm 0.58$ & $1.82 b \pm 0.36$ & $1.48 \mathrm{~b} \pm 0.50$ \\
\hline ModV8 & $1.16 \mathrm{c} \pm 0.31$ & $0.98 c \pm 0.37$ & $0.51 c \pm 0.60$ & $0.62 c \pm 0.39$ & $2.41 c \pm 0.51$ \\
\hline \multicolumn{6}{|c|}{ (B) Percent survival } \\
\hline PDA & $91.1 \pm 4.21$ & $91.1 \pm 4.21$ & $91.5 \pm 5.35$ & $91.1 \pm 4.21$ & $91.1 \pm 4.21$ \\
\hline DRBC & $90.1 \pm 4.21$ & $90.1 \pm 4.21$ & $88.2 \pm 5.35$ & $90.1 \pm 4.21$ & $90.1 \pm 4.21$ \\
\hline ModV8 & $81.5 \pm 4.37$ & $81.5 \pm 4.37$ & $80.0 \pm 5.64$ & $81.5 \pm 4.37$ & $81.5 \pm 4.37$ \\
\hline
\end{tabular}

Note: Slopes calculated from estimates for fixed effects, and standard errors, and least squares means of percent survival (growth present on each of 5 plates per isolate in each of 3 assays) and standard errors, are reported.

*PDA is half-strength potato-dextrose, commonly used for growing fungi; ModV8 is a modification of a V8-juice-based agar (see Materials and methods); DRBC (dichloran rose bengal chloramphenicol) is a commonly used medium for selection of fungi.

†For a given fungus, slopes with different letters are significantly different at $P \leq 0.05$. There were no significant differences between mean percent survival on media for any of the fungi.

Table 4. Mean numbers of Cochliobolus, Alternaria, and Fusarium species, and other fungi, isolated from field-grown sorghum grain on 4 semiselective media.

\begin{tabular}{lcccl}
\hline & \multicolumn{4}{l}{ Mean numbers of colonies per 100 grains } \\
\cline { 2 - 5 } Medium* & Cochliobolus spp. & Alternaria spp. & Fusarium spp. & Other \\
\hline DRBC & $4.1 \mathrm{a} \pm 0.8$ & $61.1 \mathrm{a} \pm 3.1$ & $2.2 \mathrm{a} \pm 0.5$ & $4.5 \mathrm{a} \pm 0.8$ \\
ModV8 & $4.4 \mathrm{a} \pm 0.8$ & $62.2 \mathrm{a} \pm 3.1$ & $2.3 \mathrm{a} \pm 0.5$ & $5.0 \mathrm{a} \pm 0.8$ \\
DCPA & $3.1 \mathrm{ab} \pm 0.8$ & $58.9 \mathrm{a} \pm 3.2$ & $1.0 \mathrm{a} \mathrm{b} \pm 0.5$ & $5.6 \mathrm{a} \pm 0.8$ \\
PCNB & $1.1 \mathrm{~b} \pm 0.8$ & $0.1 \mathrm{~b} \pm 3.1$ & $0.0 \mathrm{~b} \pm 0.5$ & $0.0 \mathrm{~b} \pm 0.8$ \\
\hline
\end{tabular}

Note: Least square means and standard errors are shown. Within a fungal group, means with different letters are significantly different at $P \leq 0.05$.

*DRBC (dichloran rose bengal chloramphenicol) is a commonly used medium for selection of fungi; ModV8 is a modification of a V8-juice-based agar (see Materials and methods); DCPA (dichloran chloramphenicol peptone agar) is a semiselective medium for Fusarium spp. and Alternaria spp. and other darkspored ascomycetes (Andrews and Pitt 1986); PCNB (pentachloronitrobenzene) is semiselective for Fusarium spp. (Nash and Snyder 1962).

larly mean conidial dimensions (length: $19.0 \pm 4.7$ to $23.1 \pm 5.3 \mu \mathrm{m}$; width: $9.0 \pm 2.0$ to $10.7 \pm 2.0 \mu \mathrm{m}$ ); relatively short, highly branched conidiophores on PCA medium; and pale olive green to tan flocculent growth on DRYES medium (daylight conditions).

The other 6 isolates did not place well in the A. alternata species complex nor in 2 other species complexes (Alternaria infectoria and Alternaria tenuissima) (Dugan and Peever 2002). The 6 isolates could be placed into 4 morphological groups, with 1 to 2 members, as determined by colony morphology on 6 media, conidial dimensions and conidiophores on PCA or water agar. Conidial dimensions ranged from 22.1 to $28.5 \mu \mathrm{m}$ (length) by 6.4 to $14.0 \mu \mathrm{m}$ (width). Conidiophores could be relatively short and unbranched or relatively long with multiple branches. Different colony morphologies on DRYES (daylight conditions) had multiple colors (offwhite, pale yellow, beige, tan, or brown) and textures (flocculent or powdery). These isolates were designated as Alternaria sp.

Amplification, sequencing, and comparisons with sequences in GenBank, using 4 loci, were conducted to determine whether isolates can be further distinguished using molecular tools. Comparisons of ITS sequences from the above listed 9 isolates indicated that all shared high sequence similarity (100\%) to A. alternata and Alternaria sp. Sequence analysis of the $\mathrm{mt} \mathrm{SSU}$ region from 8 of the 9 isolates had sequences with high similarity (100\%) to sequences from 5 species: A. alternata, Alternaria arborescens E.G. Simmons 1999, Alternaria destruens E.G. Simmons 1998, Alternaria longipes (Ellis \& Everh.) E.W. Mason 1928, and Alternaria tenuissima
(Kunze) Wiltshire 1933. A portion of the gpd gene was amplified and sequenced from 8 of the 9 isolates described above, revealing that this region from 1 isolate (No. H02-711S-2) had high similarity (99\%) to sequences from A. alternata, Alternaria dumosa E.G. Simmons 1999, and Alternaria limoniasperae E.G. Simmons 1999, while the sequences from the other 7 isolates had high similarities (100\%) to sequences from 3 Alternaria species (A. arborescens, A. destruens, and $A$. tenuissima). Sequences from a portion of endo-PG were obtained from 6 isolates (M05-1561S-5, H02-747S-5, H02-781S-3b, M05-1553S-3b, M05-1541S-1, and M05-1557S-4). Sequences from all six isolates had high similarity (99\%) to a sequence from $A$. tenuissima and most from $A$. alternata (all except M05-1541S-1). Additionally, sequences from some isolates had high similarities (99\%) to sequences from Alternaria citriarbusti E.G. Simmons 1999 (M05-1541S-1), Alternaria macrospora (Sacc.) Mussat 1900 (M05-1553S-3b), Alternaria mali Roberts 1914 (M05-1553S-3b), and Alternaria toxicogenica E.G. Simmons 1999 (M05-1561S-5, H02747S-5, H02-781S-3b, and M05-1557S-4).

\section{Morphological and molecular analyses of representative Cochliobolus-like isolates from sorghum grain}

Cochliobolus isolates chosen to represent morphological types obtained from sorghum grain were identified using the system of Sivanesan (1987). Cochliobolus includes the 2 anamorph genera, Curvularia and Bipolaris. Using conidial dimensions and conidiophore structure, isolate LP09-1 was placed in C. lunata (as previously described by Little and Magill (2003), while isolate H05-531S-2 had similarities to Curvularia sorghina R.G. Shivas \& Sivan. 1987. Isolates H05505S-1 and H05-557S-1 had characteristics consistent with Bipolaris sorghicola (Lefebvre \& Sherwin) Alcorn 1983.

Analyses of ITS, mt SSU, and gpd sequences from the 4 isolates showed that they all had high similarities (99\%-100\%) to sequences from Cochliobolus (Cochliobolus geniculatus R.R. Nelson 1964, Cochliobolus carbonum R.R. Nelson 1959, Cochliobolus victoriae R.R. Nelson 1960, Cochliobolus sativus (S. Ito \& Kurib.) Drechsler ex Dastur and Cochliobolus sp.) and Bipolaris (Bipolaris zeae Sivan. 1985) species. Additionally, LP09-1 and H05-557S-1 had high sequence similarities to Curvularia fallax Boedijn 1933, Curvularia affinis Boedijn 1933, Curvularia brachyspora Boedijn 1933, and Curvularia sp.

ITS sequences from 18 Cochliobolus isolates were compared with one another and with sequences in GenBank, and 10 ITS genotypes were distinguished. Two genotypes had high sequence similarity ( $97 \%$ and $100 \%)$ to those from C. lunatus, 2 genotypes had high sequence similarity ( $99 \%$ and $100 \%$ ) to those from Bipolaris sp., 
Table 5. Means of shoot percent discoloration, mass $(\mathrm{g})$, and lesion length $(\mathrm{mm})$, and root percent discoloration and percent recovery as determined using 2 semiselective media, following inoculation of sterile sorghum seedlings with C. lunata, Alternaria sp., F. thapsinum, a mixture of the 3 fungi, or sterile water.

\begin{tabular}{|c|c|c|c|c|c|}
\hline Measurement & $\begin{array}{l}\text { Curvularia } \\
\text { lunata }\end{array}$ & Alternaria sp. & $\begin{array}{l}\text { Fusarium } \\
\text { thapsinum }\end{array}$ & Mixture & Water \\
\hline \multicolumn{6}{|l|}{ Shoots } \\
\hline \% Discoloration & $48.8 \mathrm{c} \pm 4.8$ & $54.0 \mathrm{c} \pm 4.8$ & $81.2 \mathrm{a} \pm 4.8$ & $69.5 \mathrm{~b} \pm 4.9$ & $39.6 \mathrm{~d} \pm 5.0$ \\
\hline Mass (g) & $2.58 \mathrm{~b} \pm 0.19$ & $2.01 c \pm 0.19$ & $1.13 d \pm 0.19$ & $1.50 \mathrm{~d} \pm 0.19$ & $4.25 a \pm 0.21$ \\
\hline Lesion length (mm) & $6.53 \mathrm{~b} \pm 2.83$ & $9.95 \mathrm{ab} \pm 2.89$ & $12.72 \mathrm{a} \pm 2.95$ & $12.42 \mathrm{a} \pm 2.97$ & $1.09 \mathrm{c} \pm 2.95$ \\
\hline \multicolumn{6}{|l|}{ Roots } \\
\hline \% Discoloration & $59.8 \mathrm{bc} \pm 3.0$ & $78.0 \mathrm{a} \pm 3.1$ & $54.2 \mathrm{c} \pm 3.0$ & $64.0 \mathrm{~b} \pm 3.2$ & $17.9 \mathrm{~d} \pm 3.4$ \\
\hline \% Recovery-DRBC & $72.5 \mathrm{a} \pm 9.4$ & $76.5 a \pm 9.5$ & $37.8 \mathrm{~b} \pm 9.4$ & $27.9 b \pm 9.6$ & $1.2 c \pm 9.9$ \\
\hline \% Recovery-ModV8 & $67.9 \mathrm{a} \pm 11.6$ & $74.2 \mathrm{a} \pm 11.7$ & $29.3 \mathrm{~b} \pm 11.6$ & $34.5 b \pm 11.7$ & $0.0 \mathrm{c} \pm 12.0$ \\
\hline
\end{tabular}

Note: Conidial suspensions of each fungus, C. lunata, Alternaria sp., and F. thapsinum, and a mixture of 1 C. lunata: 1 Alternaria sp.: $1 \mathrm{~F}$. thapsinum were prepared in sterile purified water, and $1.25 \times 10^{3}$ conidia were applied at the base of the stalk of each seedling. Least square means and standard errors are reported. For each measurement, means with different letters are significantly different at $P \leq 0.05$. DRBC is a commonly used medium for selection of fungi; ModV8 is a modification of a V8-juice-based agar (see Materials and methods).

and 6 genotypes had high sequence similarity (99\%-100\%) to those from Cochliobolus sp.

\section{Discussion}

As quoted from Bragulat and associates (Bragulat et al. 1991), "one ideal medium does not exist". In the present study, a systematic approach was undertaken to determine media that would consistently allow for isolation of Cochliobolus, Alternaria, and Fusarium spp. from sorghum tissues. Cultural techniques for enumerating microorganisms allow for organisms of interest to be in-hand for further investigations. A combination of isolation of culturable fungi using semiselective media, as well as cultureindependent methods (Chistoserdova 2010), would be ideal for creating a complete picture of the interactions of fungi with different plant tissues.

A combination of nutrient bases to encourage growth of the desired fungi and antimicrobials that would inhibit growth of other fungi were chosen with the goal of increasing efficiency of isolating Cochliobolus, Alternaria, and Fusarium spp. from sorghum grain. This was achieved with DRBC and ModV8 media. DRBC is a general purpose semiselective medium for enumerating fungi. ModV8 is a modification of classic V8 juice agar, used for growing a wide variety of fungi that prefer acidic conditions and for inducing sporulation in many fungi and yeasts. DRBC, as well as DCPA and PCNB, include peptone as a nutritional source, while ModV8 includes vegetable juice for nutrients. To limit growth of unwanted microorganisms, DRBC and DCPA include the fungicide dichloran and the antibiotic chloramphenicol, although the concentrations of both antimicrobials are less in DRBC (Andrews and Pitt 1986; King et al. 1979). In addition, DRBC includes rose bengal, an indicator dye that inhibits the growth of bacteria and the spread of fungi, making it easier to enumerate individual fungal colonies (King et al. 1979; Ottow 1972). It had been suggested that fungal enzymatic release of chloride ions from rose bengal contributed to this inhibition (Hutchison 1990). PCNB, another peptone-based medium, includes the fungicide pentachloronitrobenzene, which is highly selective against many oomycetes and fungi other than Fusarium spp. (Nakanishi and Oku 1969). However, in the present study, it was found that mean numbers of Fusarium spp. isolated from sorghum grain on DRBC or ModV8 were greater than those isolated on agar medium containing PCNB.

Inoculation of sorghum seedlings with $C$. lunata conidia in a gnotobiotic system demonstrated the response of sorghum seedlings to root infection under these conditions (Table 5). Percent recovery from roots, as determined on DRBC and ModV8 media, was relatively high (73\% and $68 \%$, respectively). When a mixture of
C. lunata, F. thapsinum, and Alternaria sp. conidia was applied to seedlings, the responses from mixed infection by the 3 fungi was most similar to those resulting from infection by F. thapsinum alone (Table 5). This lack of synergism was also observed in roots of wheat or barley infected by a Fusarium sp. and a Cochliobolus sp. (Hill and Blunt 1994; Scardaci and Webster 1981) and in sorghum grain infected with a mixture of F. thapsinum and C. lunata (Prom et al. 2003). In the present study, colonies grown from root pieces plated onto semiselective media were transferred to PDA medium for identification; over half of the transfers were F. thapsinum. These results suggest that the $F$. thapsinum isolate was competitive against the C. lunata and Alternaria sp. isolates applied in this system.

Alternaria is one of the most commonly recovered fungal genera from sorghum grain (Funnell-Harris et al. 2010; Funnell and Pedersen 2006; Seitz et al. 1983; Tarekegn et al. 2006). Many smallspored Alternaria isolates are grouped together as "A. alternata" (Simmons 1999). An attempt was made in the present study to define Alternaria isolates from sorghum grain further. Superficially, most isolates appeared to be A. alternata, but a morphological screen revealed differences, particularly in configuration (length and branching patterns) of conidiophores formed on water agar. Thus, representatives of these morphological types were analyzed further using the system of Dugan and Peever (2002). By growing isolates on 6-7 different media, it was clear that 3 isolates fit well within the parameters described for the A. alternata species complex, while 4 other morphologies were observed; these isolates were designated morphologically as Alternaria sp. Analysis using sequence data from ITS, gpd, and $\mathrm{mt}$ SSU regions neither disputed nor supported these observations. Sequence analyses of these loci provide further evidence for the close relationship between A. alternata and A. tenuissima, as was observed in previous phylogenetic studies (Hong et al. 2006; Pryor and Bigelow 2003; Pryor and Michailides 2002). In particular, ITS may be problematic as a tool for species identification; because of its repetitive nature, within species as well as within individual variation may be such that difficulties arise in defining a threshold of percent identity that delineates closely related species (Begerow et al. 2010). Therefore, sequence analysis of a portion of the endo-PG gene (Peever et al. 2002) was undertaken for 6 of the isolates; adequate amplification or sequence from 3 other isolates could not be obtained. Taken together, the results allowed a conclusion, supported by morphological and endo-PG analyses, that 2 isolates were $A$. alternata (H02-747S-5 and M05-1553S-3b) and 1 was A. tenuissima (M051541S-1). Three isolates are likely to be A. tenuissima or A. alternata (M05-1561S-5, H02-781S-3b, and M05-1541S-1) while other isolates may be outside the $A$. alternata/A. tenuissima group, supported by 
differences in morphology. Thus, a combination of comparisons of morphological and endo-PG sequences allowed for further characterization of Alternaria isolates from sorghum grain. Using the system of Sivanesan (1987), different Cochliobolus isolates from sorghum grain were distinguished into morphological species. Cochliobolus, which encompasses the sexual genus and 2 asexual forms (Bipolaris and Curvularia) includes over 90 species (Berbee et al. 1999). Using ITS and gpd sequences of Cochliobolus, Curvularia, and Bipolaris spp., as well as species from closely related genera, it had been shown that Cochliobolus and its asexual genera grouped in a clade separate from species in closely related genera but the single clade formed 2 groups (Berbee et al. 1999). Cochliobolus Group 1 includes B. sorghicola as well as other Cochliobolus and Bipolaris spp. Group 2 includes $C$. lunata and other Cochliobolus, Bipolaris, and Curvularia spp. The other species identified morphologically in this study, C. sorghina, had high (99\%-100\%) sequence homology to C. carbonum (gpd, ITS), and C. victoriae (gpd), previously found to be in Group 1 along with B. sorghicola (Berbee et al. 1999). In addition to indicating molecular relationships with other species in the Cochliobolus/Bipolaris/Curvularia clade, ITS sequences may be useful for describing genotypic diversity, as 10 ITS genotypes were distinguishable among Cochliobolus isolates obtained from sorghum grain.

In summary, 2 semiselective media were found to be efficient for isolation of the grain mold fungi, Cochliobolus, Alternaria, and Fusarium spp., from sorghum. Molecular analyses of ITS regions allowed identification of multiple genotypes of Cochliobolus isolates from sorghum. The semiselective media and molecular markers are tools to allow for comprehensive, culture-dependent, and culture-independent analyses of the interactions of grain mold fungi with sorghum.

\section{Acknowledgements}

The authors thank the following for assistance with this research. P. O'Neill assisted with statistical analyses and oversaw laboratory operations; J. Toy (Nebraska) and K. Schaefer (Texas) oversaw field operations; and M. Pakes and J. Aldridge assisted in the laboratory. Mention of trade names or commercial products in this article is solely for the purpose of providing specific information and does not imply recommendation or endorsement by the U.S. Department of Agriculture. This article is in the public domain and not copyrightable. It may be freely reprinted with customary crediting of source.

\section{References}

Al-Sadi, A.M., and Deadman, M.L. 2010. Influence of seed-borne Cochliobolus sativus (anamorph Bipolaris sorokiniana) on crown rot and root rot of barley and wheat. J. Phytopathol. 158(10): 683-690. doi:10.1111/j.1439-0434.2010.01684.x.

Andrews, S., and Pitt, J.I. 1986. Selective medium for isolation of Fusarium species and dematiaceous hyphomycetes from cereals. Appl. Environ. Microbiol. 51(6): 1235-1238. PMID:3729399.

Barnett, H.L., and Hunter, B.B. 1972. Illustrated genera of imperfect fungi. 3rd ed. Burgess Publishing Co., Minneapolis, Minn., USA

Begerow, D., Nilsson, H., Unterseher, M., and Maier, W. 2010. Current state and perspectives of fungal DNA barcoding and rapid identification procedures. Appl. Microbiol. Biotechnol. 87(1): 99-108. doi:10.1007/s00253-010-2585-4. PMID:20405123.

Berbee, M.L., Pirseyedi, M., and Hubbard, S. 1999. Cochliobolus phylogenetics and the origin of known, highly virulent pathogens, inferred from ITS and glyceraldehyde-3-phosphate dehydrogenase gene sequences. Mycologia, 91(6): 964-977. doi:10.2307/3761627.

Bragulat, M.R., Abarca, M.L., Bruguera, M.T., and Cabanes, F.J. 1991. Dyes as fungal inhibitors: effect on colony diameter. Appl. Environ. Microbiol. 57(9): 2777-2780. PMID:1768153.

Carpita, N.C., and McCann, M.C. 2008. Maize and sorghum: genetic resources for bioenergy grasses. Trends Plant Sci. 13(8): 415-420. doi:10.1016/j.tplants.2008. 06.002. PMID:18650120.

Castor, L.L., and Frederiksen, R.A. 1982. Grain deterioration in sorghum. In Proceedings of the International Symposium on Sorghum Grain Quality. Edited by L.W. Rooney and D.S. Murty. ICRISAT Center, Patancheru A.P., India. pp. 163-169.

Chistoserdova, L. 2010. Recent progress and new challenges in metagenomics for biotechnology. Biotechnol. Lett. 32(10): 1351-1359. doi:10.1007/s10529010-0306-9. PMID:20495950.

Dugan, F.M., and Peever, T.L. 2002. Morphological and cultural differentiation of described species of Alternaria from Poaceae. Mycotaxon, 83: 229-264.

Ellis, M.B. 1971. Dematiaceous Hyphomycetes. Commonwealth Mycological Institute, Surrey, Great Britain.

Funnell, D.L., and Pedersen, J.F. 2006. Association of plant color and pericarp color with colonization of grain by members of Fusarium and Alternaria in near-isogenic sorghum lines. Plant Dis. 90(4): 411-418. doi:10.1094/PD-90-0411.

Funnell-Harris, D.L., and Pedersen, J.F. 2008. Inoculation strategies to assess biological interactions between Fusarium and Alternaria species infecting sorghum. Can. J. Plant Pathol. 30(3): 404-413. doi:10.1080/07060660809507538.

Funnell-Harris, D.L., Pedersen, J.F., and Sattler, S.E. 2010. Alteration in lignin biosynthesis restricts growth of Fusarium spp. in brown midrib sorghum. Phytopathology, 100(7): 671-681. doi:10.1094/PHYTO-100-7-0671. PMID: 20528185.

Hill, J.P., and Blunt, D.L. 1994. Wheat seedling response to root infection by Cochliobolus sativus and Fusarium acuminatum. Plant Dis. 78(12): 1150-1152. doi: 10.1094/PD-78-1150.

Hong, S.G., Maccaroni, M., Figuli, P.J., Pryor, B.M., and Belisario, A. 2006. Polyphasic classification of Alternaria isolated from hazelnut and walnut fruit in Europe. Mycol. Res. 110(11): 1290-1300. doi:10.1016/j.mycres.2006.08.005. PMID:17077026.

Hutchison, L.J. 1990. Studies on the systematics of ectomycorrhizal fungi in axenic culture. IV. The effect of some selected fungitoxic compounds upon linear growth. Can. J. Bot. 68(10): 2172-2178. doi:10.1139/b90-283.

King, J.A.D., Hocking, A.D., and Pitt, J.I. 1979. Dichloran-rose bengal medium for enumeration and isolation of molds from foods. Appl. Environ. Microbiol. 37(5): 959-964. PMID:485140.

Klittich, C.J.R., Leslie, J.F., Nelson, P.E., and Marasas, W.F.O. 1997. Fusarium thapsinum (Gibberella thapsina): a new species in section Liseola from sorghum. Mycologia, 89(4): 643-652. doi:10.2307/3761002.

Lee, S.B., and Taylor, J.W. 1990. Isolation of DNA from fungal mycelia and single spores. In PCR protocols: a guide to methods and applications. Edited by M.A. Innis, D.H. Gelfand, J.J. Sninsky, and T.J. White. Harcourt, Brace Jovanovich, Publishers, San Diego, Calif., USA. pp. 282-287.

Leslie, J.F., and Summerell, B.A. 2006. The Fusarium laboratory manual. Blackwell Publishing, Ames, Iowa.

Li, K.-N., Rouse, D.I., and German, T.L. 1994. PCR primers that allow intergeneric differentiation of ascomycetes and their application to Verticillium spp. Appl. Environ. Microbiol. 60(12): 4324-4331. PMID:7811072.

Lincy, S.V., Chandrashekar, A., Narayan, M.S., Sharma, R., and Thakur, R.P. 2011. Natural occurrence of trichothecene-producing fusaria isolates from India with particular reference to sorghum. World J. Microbiol. Biotechnol. 27(4): 981-989. doi:10.1007/s11274-010-0542-0.

Little, C.R., and Magill, C.W. 2003. Elicitation of defense response genes in sorghum floral tissues infected by Fusarium thapsinum and Curvularia lunata at anthesis. Physiol. Mol. Plant Pathol. 63(5): 271-279. doi:10.1016/j.pmpp.2004. 02.001.

Little, C.R., Perumal, R., Tesso, T., Prom, L.K., Odvody, G.N., and Magill, C.W. 2012. Sorghum pathology and biotechnology a fungal disease perspective: Part I. Grain mold, head smut and ergot. Eur. J. Plant Sci. Biotechnol. 6(1): 10-30.

Menkir, A., Ejeta, G., Butler, L.G., Melakeberhan, A., and Warren, H.L. 1996. Fungal invasion of kernels and grain mold damage assessment in diverse sorghum germplasm. Plant Dis. 80(12): 1399-1402. doi:10.1094/PD-80-1399.

Murillo-Williams, A., and Munkvold, G.P. 2008. Systemic infection by Fusarium verticillioides in maize plants grown under three temperature regimes. Plant Dis. 92(12): 1695-1700. doi:10.1094/PDIS-92-12-1695.

Nakanishi, T., and Oku, H. 1969. Metabolism and accumulation of pentachloronitrobenzene by phytopathogenic fungi in relation to selective toxicity. Phytopathology, 59(11): 1761-1762. PMID:5377742.

Nash, S.M., and Snyder, W.C. 1962. Quantitative estimations by plate counts of propagules of the bean root rot Fusarium in field soils. Phytopathology, 52(6): 567-572.

Navi, S.S., Bandyopadhyay, R., Reddy, R.K., Thakur, R.P., and Yang, X.B. 2005. Effects of wetness duration and grain development stages on sorghum grain mold infection. Plant Dis. 89(8): 872-878. doi:10.1094/PD-89-0872.

Nelson, P.E., Toussoun, T.A., and Marasas, W.F.O. 1983. Fusarium species: an illustrated manual for identification. The Pennsylvania State University Press, University Park, Penn., USA.

O’Donnell, K., Cigelnik, E., and Nirenberg, H.I. 1998. Molecular systematics and phylogeography of the Gibberella fujikuroi species complex. Mycologia, 90(3): 465-493. doi:10.2307/3761407.

Ottow, J.C.G. 1972. Rose bengal as a selective aid in the isolation of fungi and actinomycetes from natural sources. Mycologia, 64(2): 304-315. doi:10.2307| 3757834. PMID:5019274.

Pedersen, J.F., and Toy, J.J. 2001. Registration of N321-N340 sorghum seed color/ plant color genetic stocks. Crop Sci. 41(2): 607. doi:10.2135/cropsci2001. 412607x.

Peever, T.L., Ibanez, A., Akimitsu, K., and Timmer, L.W. 2002. Worldwide phylogeography of the citrus brown spot pathogen, Alternaria alternata. Phytopathology, 92(7): 794-802. doi:10.1094/PHYTO.2002.92.7.794. PMID:18943277. 
Pratt, R.G. 2006. Comparative survival of conidia of eight species of Bipolaris, Curvularia and Exserohilum in soil and influences of swine waste amendments on survival. Appl. Soil Ecol. 31(1-2): 159-168. doi:10.1016/j.apsoil.2005.03.005.

Prom, L.K., Waniska, R.D., Kollo, A.I., and Rooney, W.L. 2003. Response of eight sorghum cultivars inoculated with Fusarium thapsinum, Curvularia lunata, and a mixture of the two fungi. Crop Prot. 22(4): 623-628. doi:10.1016/S02612194(02)00246-6.

Pryor, B.M., and Bigelow, D.M. 2003. Molecular characterization of Embellisia and Nimbya species and their relationship to Alternaria, Ulocladium and Stemphylium. Mycologia, 95(6): 1141-1154. doi:10.2307/3761916. PMID:21149017.

Pryor, B.M., and Michailides, T.J. 2002. Morphological, pathogenic, and molecular characterization of Alternaria isolates associated with Alternaria late blight of pistachio. Phytopathology, 92(4): 406-416. doi:10.1094/PHYTO.2002.92.4. 406. PMID:18942954.

Rabie, C.J., Lubben, A., Marais, G.J., and Jansen van Vuuren, H. 1997. Enumeration of fungi in barley. Int. J. Food Microbiol. 35(2): 117-127. doi:10.1016/S01681605(96)01210-X. PMID:9105919.

Sarath, G., Mitchell, R.B., Sattler, S.E., Funnell, D., Pedersen, J.F., Graybosch, R.A., and Vogel, K.P. 2008. Opportunities and roadblocks in utilizing forages and small grains for liquid fuels. J. Ind. Microbiol. Biotechnol. 35(5): 343-354. doi:10.1007/x10295-007-0296-3. PMID:18205019.

SAS Institute Inc. 2002-2008. SAS/STAT user's guide. Version 9.2 [computer program]. SAS Institute Inc., Cary, N.C., U.S.A.

Scardaci, S., and Webster, R.K. 1981. Antagonism between the cereal root rot pathogens Fusarium graminearum and Bipolaris sorokiniana. Plant Dis. 65(12): 965-967. doi:10.1094/PD-65-965.

Seitz, L.M., Mohr, H.E., Burroughs, R., and Glueck, J.A. 1983. Preharvest fungal invasion of sorghum grain. Cereal Chem. 60(2): 127-130.

Sharma, R., Rao, V.P., Upadhyaya, H.D., Gopal Reddy, V., and Thakur, R.P. 2010. Resistance to grain mold and downy mildew in a mini-core collection of sorghum germplasm. Plant Dis. 94(4): 439-444. doi:10.1094/PDIS-94-4-0439.

Sharma, R., Thakur, R.P., Senthilvel, S., Nayak, S., Reddy, S.V., Rao, V.P., and Varshney, R.K. 2011. Identification and characterization of toxigenic fusaria associated with sorghum grain mold complex in India. Mycopathologia, 171(3): 223-230. doi:10.1007/s11046-010-9354-x. PMID:20694855.
Simmons, E.G. 1967. Typification of Alternaria, Stemphylium and Ulocladium. Mycologia, 59(1): 67-92. doi:10.2307/3756943. PMID:6068270.

Simmons, E.G. 1990. Alternaria themes and variations (27-53). Mycotaxon, 37: 79-119.

Simmons, E.G. 1999. Alternaria themes and variations (226-235): Classification of citrus pathogens. Mycotaxon, 70: 263-323.

Simmons, E.G. 2007. Alternaria: an identification manual. CBS Fungal Biodiversity Centre, Utrect, the Netherlands.

Simmons, E.G., and Roberts, R.G. 1993. Alternaria themes and variations (73). Mycotaxon, 48: 109-140.

Sivanesan, A. 1987. Graminicolous species of Bipolaris, Curvularia, Dreschlera, Exserohilum and their teleomorphs. Mycol. Pap. 158: 1-261.

Stack, J.P., and Pedersen, J.F. 2003. Expression of susceptibility to Fusarium head blight and grain mold in $\mathrm{A}_{1}$ and $\mathrm{A}_{2}$ cytoplasms of Sorghum bicolor. Plant Dis. 87(2): 172-176. doi:10.1094/PDIS.2003.87.2.172.

Tarekegn, G., McLaren, N.W., and Swart, W.J. 2006. Effects of weather variables on grain mould of sorghum in South Africa. Plant Pathol. 55(2): 238-245. doi:10.1111/j.1365-3059.2005.01333.x.

Taylor, J.R.N., Schober, T.J., and Bean, S.R. 2006. Novel food and non-food uses for sorghum and millets. J. Cereal Sci. 44(3): 252-271. doi:10.1016/j.jcs.2006.06. 009.

White, T.J., Bruns, T., Lee, S., and Taylor, J. 1990. Amplification and direct sequencing of fungal ribosomal RNA genes for phylogenetics. In PCR protocols: a guide to methods and applications. Edited by M.A. Innis. Academic Press, San Diego, Calif., USA. pp. 315-322.

Wilson, J.P. 2002. Fungi associated with the stalk rot complex of pearl millet. Plant Dis. 86(8): 833-839. doi:10.1094/PDIS.2002.86.8.833.

Windels, C.E., Burnes, P.M., and Kommedahl, T. 1988. Five-year preservation of Fusarium species on silica gel and soil. Phytopathology, 78(1): 107-109. doi:10. 1094/Phyto-78-107.

Yang, S.-m. 1973. Isolation and effect of temperature on spore germination, radial growth, and pathogenicity of Curvularia senegalensis. Phytopathology, 63(12): 1541-1542. doi:10.1094/Phyto-63-1541. 